\title{
Evaluation of Clinical Profile of Bipolar and Unipolar Depression Patients- A Clinical Study
}

\author{
Musuku Srikanth Reddy ${ }^{\odot}$ \\ Assistant Professor, Department of Psychiatry, Kamineni Medical College, Narketpally, Telangana, India.
}

\section{Abstract}

Background: The present study was conducted to assess the clinical profile of unipolar and bipolar depressive patients. Subjects \& Methods: 74 patients diagnosed with unipolar (40) and bipolar (34) depressive disorders were selected. Depressive cognitions, catatonic features, suicidal thoughts, anhedonia, pseudodementia, dissociative features, panic attacks, delusions, first-rank symptoms, auditory hallucinations, and affective reactivity were recorded. Results: Out of 74 patients, males were 32 and females were 42 . Age of onset was 32.2 years in group I and 20.4 years in group II, total duration was 12.4 years in group I and 16.2 years in group II, the number of episodes was 3.4 and 7.1 in group II, the number of hospitalizations was 2.8 in group I and 5.2 in group II, suicidal thoughts were seen in 21 in group I and 24 in group II, anhedonia 10 in group I and 23 in group II, psuedodementia 7 in group I and 13 in group II, dissociative features were seen in 11 in group I and 27 in group II, delusions 4 in group I and 8 in group II, panic symptoms 10 in group I and 18 in group II and auditory hallucination 7 in group I and 18 in group II. The difference was significant $(\mathrm{P}<0.05)$. Conclusion: Authors found that common clinical features were suicidal thoughts, dissociative features, and anhedonia.

Keywords: Anhedonia, Bipolar depressive disorders, Suicidal thoughts.

Corresponding Author: Musuku Srikanth Reddy, Assistant Professor, Department of Psychiatry, Kamineni Medical College, Narketpally, Telangana, India.

E-mail: jgdjmrjsmj@gmail.com

Received: 25 September 2020

Published: 31 December 2020

\section{Introduction}

Unipolar (UP) and bipolar (BP) disorders differ in genetics, neurobiology, clinical course, treatment regimens and prognosis. ${ }^{[1]}$ Approximately, $40 \%$ of patients with BP affective disorder (BPAD) initially receive an incorrect diagnosis of recurrent depressive disorder (RDD). Accurate diagnosis of BP depression is complicated by three factors-Assumption of similar phenomenology for BP and UP depression, failure of therapists to recognize previous hypomanic symptoms, and failure of patients to report them. ${ }^{[2]}$ The use of antidepressant monotherapy for BP depression increases the risk of a manic switch, mixed state, rapid cycling, poor or partial response, and resistance to antidepressant therapy. ${ }^{[3]}$

It is now known that the use of antidepressants in bipolar depression can lead to manic switches, mixed state induction and cycle acceleration. Studies have also shown that ECT has equal efficacy and leads to similar symptomatic and functional recovery in unipolar and bipolar depression and probable patients with bipolar depression respond faster than those with unipolar depression. ${ }^{[4]}$
Depressive episodes with sudden onset, psychomotor retardation, diurnal mood variation, worthlessness, anhedonia, pathological guilt, suicidal thoughts, psychotic symptoms, atypical features, and labile mood are important markers for bipolarity. Efficacy of ECT in the manic phase in terms of remission or marked clinical improvement has been reported to be about $80 \%$. It is also reported to be equally or more efficacious than psychotropic medications like lithium, chlorpromazine, and haloperidol. ${ }^{[5]}$ The present study was conducted to assess the clinical profile of unipolar and bipolar depressive patients.

\section{Subjects and Methods}

The present study was conducted in the Department of Psychiatry. It comprised of 74 patients diagnosed with unipolar (40) and bipolar (34) depressive disorders of both genders. The consent was obtained from the institutional ethical committee. All were informed regarding the study and their consent was obtained. 
Data such as name, age, gender, education, occupation, marital status, religion, socioeconomic status, total duration, mood chart, hospitalizations, substance abuse/dependence, deliberate self-harm, postpartum/perimenstrual behavioral disturbances, history of electroconvulsive therapy and family history of psychiatric illness in first and second-degree relatives were included. Depressive cognitions, catatonic features, suicidal thoughts, anhedonia, pseudodementia, dissociative features, panic attacks, delusions, first-rank symptoms, auditory hallucinations, and affective reactivity were recorded. Results were tabulated and subjected to statistical analysis. A p-value of less than 0.05 was considered significant.

\section{Results}

Table 1: Distribution of patients

\begin{tabular}{|lll|}
\hline Total- 74 & & \\
\hline Gender & Males & Females \\
\hline Number & 32 & 42 \\
\hline
\end{tabular}

[Table 1] shows that out of 74 patients, males were 32 and females were 42.

\begin{tabular}{|llll|}
\hline \multicolumn{4}{|c|}{ Table 2: Clinical profile of unipolar and bipolar patients } \\
\hline $\begin{array}{l}\text { Clinical } \\
\text { profile }\end{array}$ & $\begin{array}{l}\text { Unipolar } \\
\mathbf{( 4 0 )}\end{array}$ & $\begin{array}{l}\text { Bipolar } \\
\mathbf{( 3 4 )}\end{array}$ & P-value \\
\hline $\begin{array}{l}\text { Age of onset } \\
32.2\end{array}$ & 20.4 & 0.01 \\
\hline $\begin{array}{l}\text { Total dura- } \\
\text { tion }\end{array}$ & 12.4 & 16.2 & 0.05 \\
\hline $\begin{array}{l}\text { Number of } \\
\text { episodes }\end{array}$ & 3.4 & 7.1 & 0.02 \\
\hline $\begin{array}{l}\text { No. of hospi- } \\
\text { talizations }\end{array}$ & 2.8 & 5.2 & 0.02 \\
\hline $\begin{array}{l}\text { Suicidal } \\
\text { thoughts }\end{array}$ & 21 & 24 & 0.92 \\
\hline $\begin{array}{l}\text { Anhedonia } \\
\text { Psuedodement }\end{array}$ & 7 & 23 & 0.01 \\
\hline $\begin{array}{l}\text { Dissociative } \\
\text { features }\end{array}$ & 11 & 13 & 0.03 \\
\hline $\begin{array}{l}\text { Delusions } \\
\text { Panic symp- }\end{array}$ & 4 & 27 & 0.04 \\
toms & 10 & 18 & 0.02 \\
\hline $\begin{array}{l}\text { Auditory } \\
\text { hallucina- } \\
\text { tion }\end{array}$ & 7 & 18 & 0.04 \\
\hline
\end{tabular}

[Table 2] shows that age of onset was 32.2 years in group I and 20.4 years in group II, total duration was 12.4 years in group I and 16.2 years in group II, the number of episodes was 3.4 and 7.1 in group II, the number of hospitalizations was 2.8 in group I and 5.2 in group II, suicidal thoughts were seen in 21 in group I and 24 in group II, anhedonia 10 in group I and 23 in group II, psuedodementia 7 in group I and 13 in group II, dissociative features were seen in 11 in group I and 27 in group II, delusions 4 in group I and 8 in group II, panic symptoms 10 in group I and 18 in group II and auditory hallucination 7 in group I and 18 in group II. The difference was significant $(\mathrm{P}<$ $0.05)$.

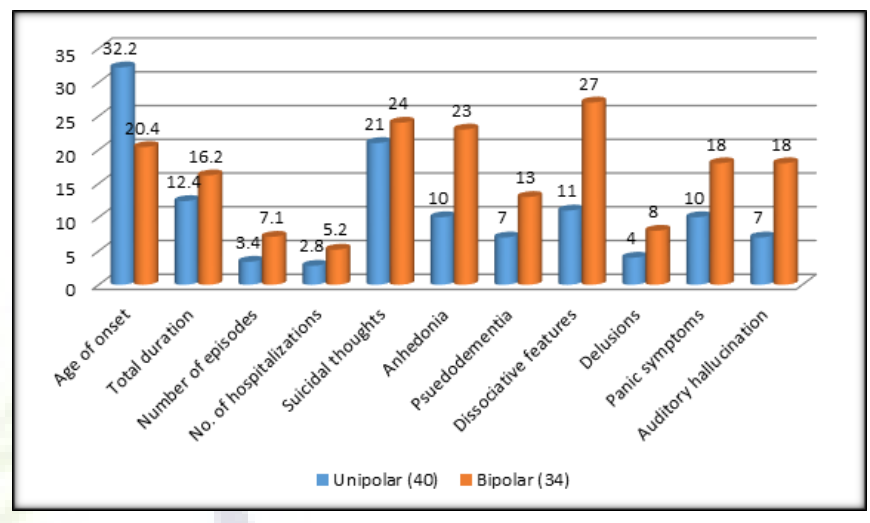

Figure 1: Clinical profile of unipolar and bipolar patients

\section{Discussion}

Distinguishing between bipolar disorder and major depressive disorder is of great clinical importance because optimal management of the two conditions is very different. ${ }^{[6]}$ For example, antidepressants should be used with caution in bipolar depression because of the risk of precipitating mood switches, cycling, or mixed or agitated states. ${ }^{[7]}$ Clinicians should use all available information to guide management (including choice of treatment, advice to patient and intensity of monitoring). The clinical features of depression are not a definitive guide to diagnosis but can help to alert the clinician to a possible bipolar course. ${ }^{[8]}$ These findings also have important implications for future research on type II bipolar disorder and sub-threshold bipolar disorders. Evidence suggests that $25-50 \%$ of individuals with recurrent major depression (particularly those within atypical, early-onset or treatment-refractory subgroups) may in fact have a broadly defined bipolar disorder. ${ }^{[9]}$ The present study was conducted to assess the clinical profile of unipolar and bipolar depressive patients.

In the present study out of 74 patients, males were 32 and females were 42 . Forty et al, ${ }^{[10]}$ found that the proportions of women in the major depression group and the bipolar group were $70.2 \%$ and $71.3 \%$ respectively. The median age at the interview was 49 years for the major depression group and 
47 years for the bipolar group. Forty-six percent of the major depression group were recruited systematically, compared with $37 \%$ of the bipolar group. The median illness duration was 19 years for the major depression group and 20 years for the bipolar group. The major depression group had a median BDI score at the interview of 16 , compared with 8 in the bipolar group.

We found that We found that age of onset was 32.2 years in group I and 20.4 years in group II, total duration was 12.4 years in group I and 16.2 years in group II, the number of episodes was 3.4 and 7.1 in group II, the number of hospitalizations was 2.8 in group I and 5.2 in group II, suicidal thoughts were seen in 21 in group I and 24 in group II, anhedonia 10 in group I and 23 in group II, psuedodementia 7 in group I and 13 in group II, dissociative features were seen in 11 in group I and 27 in group II, delusions 4 in group I and 8 in group II, panic symptoms 10 in group I and 18 in group II and auditory hallucination 7 in group I and 18 in group II. Bhardwaj et al, ${ }^{[11]}$ found that among all the patients who received ECT, $18 \%$ were diagnosed to have bipolar disorder. ECT was administered most commonly for mania with psychotic symptoms, followed by severe depression with psychotic symptoms. Comorbid physical problems were seen in many patients. Nearly $90 \%$ of patients in both the subgroups showed more than $50 \%$ response (based on reduction in the standardized rating scales) with ECT. Few patients (22\%) reported some kind of side effects. ECT is useful in the management of the acute phase of mania and depression.

Nisha et al, ${ }^{[12]}$ compared 30 UP and 30 BP depression patients using a specially designed intake proforma, International Classification of Diseases-10 diagnostic criteria for research, Hamilton Rating Scale for Depression-21 (HAMD21), Hypomania Checklist-32 Questionnaire (HCL-32), Brief psychiatric rating scale (BPRS), and Kuppuswami's socioeconomic status scale. BP depression group consisted of mostly males, with earlier age of onset of illness, longer illness duration, frequent episodes, hospitalizations and psychotic symptoms. The total HAM-D score and 4 HAM-D item scorespsychomotor retardation, insight, diurnal variation of symptoms and its severity, and paranoid symptoms were significantly higher in this group. Binary logistic regression identified the age of onset, the total duration of illness, frequency of affective episodes, and the presence of delusions as predictors of bipolarity.

The limitation of the study was a small sample size.

\section{Conclusion}

The authors found that common clinical features were suicidal thoughts, dissociative features and anhedonia.

\section{References}

1. Sharma V, Khan M, Smith A. A closer look at treatment resistant depression: is it due to a bipolar diathesis? J Affect Disord. 2005;84(2-3):251-257. Available from: https://dx.doi. org/10.1016/j.jad.2004.01.015.

2. Beck A, Steer R. and others, editor; 1987.

3. Wing J, Babor M, Brugha T, Burke J, Cooper J, Giel R, et al. SCAN: Schedules for Clinical Assessment in Neuropsychiatry. Arch Gen Psychiatry. 1990;47:589-93. Available from: https: //doi.org/10.1001/archpsyc.1990.01810180089012.

4. Cuellar AK, Johnson SL, Winters R. Distinctions between bipolar and unipolar depression. Clin Psychol Rev. 2005;25(3):307-339. Available from: https://dx.doi.org/10. 1016/j.cpr.2004.12.002.

5. Mcguffin P, Farmer A, Harvey I. A polydiagnostic application of operational criteria in studies of psychotic illness. Development and reliability of the OPCRIT system. Arch Gen Psychiatry. 1991;48:764-70. Available from: https://doi.org/10.1001/ archpsyc.1991.01810320088015.

6. Craddock M, Asherson P, Owen MJ, Williams J, Mcguffin P, Farmer AE. Concurrent validity of the OPCRIT diagnostic system. Comparison of OPCRIT diagnoses with consensus best-estimate lifetime diagnoses. Br J Psychiatry. 1996; 169:58 63. Available from: https://doi.org/10.1192/bjp.169.1.58.

7. Bowden CL. A different depression: clinical distinctions between bipolar and unipolar depression. J Affect Disord. 2005;84(2-3):117-125. Available from: https://dx.doi.org/10. 1016/s0165-0327(03)00194-0.

8. Swann AC, Geller B, Post RM, Altshuler L, Chang KD, DelBello MP, et al. Practical Clues to Early Recognition of Bipolar Disorder. J Clin Psychiatry. 2005;07(01):15-21. Available from: https://dx.doi.org/10.4088/pcc.v07n0103.

9. Mitchell PB, Wilhelm K, Parker G, Austin MP, Rutgers P, Malhi GS. The clinical features of bipolar depression: a comparison with matched major depressive disorder patients. J Clin Psychiatry. 2001;62:212-228.

10. Forty L, Smith D, Jones L, Jones I, Caesar S, Cooper C, et al. Clinical differences between bipolar and unipolar depression. Br J Psychiatry. 2008;192(5):388-389. Available from: https: //dx.doi.org/10.1192/bjp.bp.107.045294.

11. Grover S, Chakrabarti S, Avasthi A, Kate N, Bharadwaj V. Clinical profile and outcome of bipolar disorder patients receiving electroconvulsive therapy: A study from north India. Indian J Psychiatry. 2012;54:41-41. Available from: https: //dx.doi.org/10.4103/0019-5545.94644.

12. Nisha A, Sathesh V, Punnoose V, Varghese P. A comparative study on psycho-socio-demographic and clinical profile of patients with bipolar versus unipolar depression. Indian $\mathrm{J}$ Psychiatry. 2015;57:392. Available from: https://dx.doi.org/10. 4103/0019-5545.171842. 
Copyright: (C) the author(s), 2020. It is an open-access article distributed under the terms of the Creative Commons Attribution License (CC BY 4.0), which permits authors to retain ownership of the copyright for their content, and allow anyone to download, reuse, reprint, modify, distribute and/or copy the content as long as the original authors and source are cited.

How to cite this article: Reddy MS. Evaluation of Clinical Profile of Bipolar and Unipolar Depression Patients- A Clinical Study. Asian J. Med. Res. 2020;9(4):1-4.

DOI: dx.doi.org/10.47009/ajmr.2020.9.4.PY1

Source of Support: Nil, Conflict of Interest: None declared. 